\title{
Determination of the oxygen affinities of terminal oxidases in Azotobacter vinelandii using the deoxygenation of oxyleghaemoglobin and oxymyoglobin: cytochrome bd is a low-affinity oxidase
}

\author{
Rita D'Mello, ${ }^{1}$ Susan Hill ${ }^{2}$ and Robert K. Poole ${ }^{1}$
}

Author for correspondence: Robert K. Poole. Tel: +44 713334275 . Fax: +44713334500.

1 Division of Life Sciences, Kings College London, Campden Hill Road, London W8 7AH, UK

2 Nitrogen Fixation Laboratory, AFRC IPSR, University of Sussex Brighton BN1 9RQ, UK

\begin{abstract}
Azotobacter vinelandif is an obligately aerobic diazotrophic bacterium with two known terminal oxidases of the cytochrome o- and bd-types. The latter is required for respiratory protection of the oxygen-labile nitrogenase during aerotolerant nitrogen fixation. The apparent affinities $\left(K_{m}\right)$ for oxygen uptake by $A$. vinelandii cells and membranes respiring DL-malate have been determined by using the deoxygenation of oxyleghaemoglobin or oxymyoglobin as sensitive reporters of dissolved oxygen concentration. Dualwavelength spectrophotometery allowed continuous recording of oxygen consumption over the range 0.003-10 $\mu \mathrm{M}$, and revealed three distinct affinities for oxygen in a wild-type strain. The kinetic properties of each oxidase were distinguished by the use of two mutants, one lacking and one over-producing the cytochrome bd-type oxidase. The deoxygenation kinetics of oxyleghaemoglobin revealed a high affinity oxidase in all three strains with $K_{m}$ values for membrane preparations of 0.013-0.019 $\mu \mathrm{M}$. In strains having the cytochrome bd-type oxidase, the $K_{m}$ values measured with intact cells were approximately fourfold higher than in membranes. These results suggest a barrier to the transfer of oxygen to the high affinity component by cytochrome bd, perhaps due to very fast oxygen binding or scavenging by cytochrome $d$, or to the location of the oxygen-consuming sites of these oxidases on different faces of the membrane. The deoxygenation kinetics of oxymyoglobin revealed the presence of two components with mean $K_{m}$ values of about 0.33 and $4.5 \mu \mathrm{M}$. The $4.5 \mu \mathrm{M}$ component is attributed to the cytochrome bd-type oxidase because it was lacking in intact cells and membranes of the cytochrome bd-deficient mutant strain. The other two components (one with a mean $K_{\mathrm{m}}$ value of about $0.33 \mu \mathrm{M}$ and the highest affinity activity) could not be assigned to particular oxidase(s). The results are interpreted in relation to the physiological role of the cytochrome bdterminated branch of the respiratory chain and the much higher affinities for oxygen reported for the cytochrome bd-type oxidase in other bacteria.
\end{abstract}

Keywords: Azotobacter vinelandii, cytochrome $b d$, oxygen affinity, respiratory protection, deoxygenation

\section{INTRODUCTION}

The ability to fix dinitrogen is restricted to prokaryotes, and is found in obligate and facultative anaerobes, and obligate aerobes. All nitrogenases so far examined are extremely $\mathrm{O}_{2}$-sensitive (Robson \& Postgate, 1980) and require large amounts of ATP and a source of low- potential electrons for activity. Understanding the physiology whereby an aerobic catabolism is combined with the anaerobiosis required for nitrogenase function is an active area of research (Hill, 1988). Much of the early work (reviewed in Haddock \& Jones, 1977; Yates, 1988) involved descriptive biochemistry and physiology of respiration in Azotobacter, an obligate aerobe that can fix 
nitrogen aerobically. This organism has one of the highest known rates of respiration, and the ability to alter its $\mathrm{O}_{2}$ consumption so as to match wide variations in $\mathrm{O}_{2}$ supply.

The respiratory chain of Azotobacter vinelandii terminates in two $\mathrm{O}_{2}$-reducing pathways (Haddock \& Jones, 1977). One branch, thought to be composed of cytochromes $c_{4}$, $c_{5}, a_{1}$ and 0 , is terminated by an oxidase of the 0 -type, which has remained poorly characterized despite attempts to purify it (Jurtshuk et al., 1981; Yang, 1986). The phenotypes of $A$. vinelandii mutants isolated after chemical treatment (McInery et al., 1984; Hoffman et al., 1979) suggest that the cytochrome 0 -type oxidase has a role in maximizing the efficiency of energy conservation during $\mathrm{O}_{2}$-limited growth.

The alternative branch is terminated by a cytochrome $b d$ type oxidase, which is similar to that of Escherichia coli (Poole, 1988) in its spectral and ligand binding properties (reviewed by Poole, 1983). A preliminary report (Junemann \& Wrigglesworth, 1993) describes the purification and $\mathrm{CO}$ reactions of the cytochrome $b d$-type oxidase from A. vinelandii, but the kinetic properties of the purified oxidase have not been described. Kelly et al. (1990) cloned fragments of $A$. vinelandii chromosomal DNA homologous to the $c y d A B$ genes of $E$. coli, encoding the two polypeptides of the cytochrome $b d$ oxidase complex in that organism. Subsequently, Moshiri et al. (1991) cloned and sequenced the $A$. vinelandii cyd $A B$ genes and showed that they were 69 and $68 \%$, respectively, identical to the $E$. coli $c y d A$ and $c y d B$ genes. The cloned $c y d$ genes were used by Kelly et al. (1990) to construct mutants affected in cytochrome $b d$ expression and demonstrate that this oxidase was essential for aero-tolerant nitrogen fixation, as had been suggested by earlier growth experiments (Drozd \& Postgate, 1970; Haaker \& Veeger, 1976). One such mutant (MK5) was totally defective in expression of cytochrome $d$ and the spectral signals previously attributed to cytochrome ' $a_{1}$ ' and a $b$-type cytochrome, indicating that the cytochrome ' $a_{1}$ '-like band is due to a high-spin $b$-type cytochrome that is part of the cytochrome $b d$ complex (as in E. coll) and not a component of the cytochrome $c_{4} c_{5} 0$ branch as proposed in early schemes (Haddock \& Jones, 1977). A second class of mutant, typified by $\mathrm{MK} 8$, having transposon insertions upstream of the structural genes, exhibited enhanced expression of this oxidase.

There have been relatively few studies of the oxygen affinities of bacterial terminal oxidases, and most such studies have utilized insensitive polarographic methods in which the response at low oxygen tensions is limited by the 'unstirred layer' at the electrode membrane (Lundsgaard et al., 1978). The purified cytochrome bd-type oxidase isolated from Klebsiella pneumoniae, a nitrogenfixing relative of $E$. coli, has an exceptionally high affinity for oxygen (Smith et al., 1990), as appears to be the case for cytochrome $b d$ in whole organisms of $E$. coli (Rice \& Hempfling, 1978). However, the kinetics of $\mathrm{O}_{2}$ uptake by whole organisms or membranes of Azotobacter strains suggest that the $\mathrm{O}_{2}$ affinity is relatively low (Hoffman et al., 1979; Ramos \& Robson, 1985; Peterson, 1989), although Bergerson \& Turner (1980) reported $K_{\mathrm{m}}$ values of 0.48 and $35 \mu \mathrm{M}$ for $A$. vinelandii. However, these values were not assigned to particular oxidase(s). Interestingly, expression of cytochrome $d$ in Azotobacter increases in response to elevated $\mathrm{O}_{2}$ supply (Drozd \& Postgate, 1970; reviewed by Hill, 1992), whereas in E. coli expression decreases when aeration rate increases (Poole, 1983; Cotter et al., 1990).

Recognizing the crucial role of the cytochrome $b d$-type oxidase in $A$. vinelandii (Kelly et al., 1990), and yet the absence of reliable data on its oxygen affinity, we have measured the $K_{\mathrm{m}}$ values for oxygen using a wild-type strain and two classes of mutants to distinguish between the oxidase activities. A highly sensitive spectrophotometric means of continuously monitoring oxygen depletion, as reported by the deoxygenation of oxyleghaemoglobin or oxymyoglobin, has been used.

\section{METHODS}

Bacteria, growth and preparation of cell suspensions. The strains of $A$. vinelandii have been described by Kelly et al. (1990). UW136 is a wild-type strain. In mutant MK5 (Cyd $\left.{ }^{-}\right)$, the insertion of Tn5-B20 in $c y d B$ results in loss of aero-tolerant nitrogen fixation and all spectroscopically detectable components of the cytochrome $b d$ complex; in mutant $\mathrm{MK} 8\left(\mathrm{Cyd}^{++}\right)$, the insertion of $\operatorname{Tn} 5-\mathrm{B} 20$ adjacent to $c y d A B$ results in overexpression of the cytochrome $b d$ complex. Bacteria were grown in Burk's sucrose medium, supplemented with nitrogen as $15 \mathrm{mM}$ ammonium acetate (BSN medium). The medium contained $\left(\mathrm{l}^{-1}\right)$ : $10 \mathrm{ml}$ Solution I $\left[\mathrm{K}_{2} \mathrm{HPO}_{4}\left(80 \mathrm{~g} \mathrm{l}^{-1}\right), \mathrm{KH}_{2} \mathrm{PO}_{4}\right.$ $\left(20 \mathrm{~g} \mathrm{l}^{-1}\right)$ and $\left.\mathrm{Na}_{2} \mathrm{SO}_{4}\left(18.3 \mathrm{~g} \mathrm{l}^{-1}\right)\right] ; 1 \mathrm{ml}$ Solution II $\left[\mathrm{MgCl}_{2} \cdot 6 \mathrm{H}_{2} \mathrm{O}\left(160 \mathrm{~g} \mathrm{l}^{-1}\right)\right.$ and $\left.\mathrm{CaCl}_{2} \cdot 2 \mathrm{H}_{2} \mathrm{O}\left(73 \mathrm{~g} \mathrm{l}^{-1}\right)\right] ; 1 \mathrm{ml}$ Solution III $\left[\mathrm{FeSO}_{4} .7 \mathrm{H}_{2} \mathrm{O}\left(5 \mathrm{~g} \mathrm{l}^{-1}\right), \mathrm{NaMoO}_{4} .2 \mathrm{H}_{2} \mathrm{O}\left(2 \mathrm{~g} \mathrm{l}^{-1}\right)\right.$ and concentrated $\mathrm{HCl}(2 \mathrm{ml})] ; 100 \mathrm{ml}$ sucrose solution $\left(200 \mathrm{~g} \mathrm{l}^{-1}\right)$; and $10 \mathrm{ml}\left(\mathrm{NH}_{4}\right)_{3} \mathrm{OOC}-\mathrm{CH}_{3}$ solution $\left(110 \mathrm{~g} \mathrm{l}^{-1}\right)$. Solution I was diluted approximately 100 -fold before the other solutions, each separately autoclaved (except Solution III and the ammonium acetate, which were filter-sterilized), were added aseptically. Solid medium for strain maintenance also contained Bacto-agar $\left(15 \mathrm{~g} \mathrm{l}^{-1}\right)$. Media were supplemented with kanamycin $\left(1 \mu \mathrm{g} \mathrm{ml}^{-1}\right)$ for mutants MK5 and MK8.

Small-scale starter cultures of all strains were grown aerobically in unbaffled Erlenmeyer flasks, containing 1/5-1/4 their volume of medium, at $30^{\circ} \mathrm{C}$ with rotary shaking (180 r.p.m.). For large-scale culture, $10 \mathrm{l}$ of medium in a $12 \mathrm{l}$ Braun Biostat fermenter was inoculated with $500 \mathrm{ml}$ of a $9 \mathrm{~h}$ flask culture, which in turn had been inoculated with $100 \mathrm{ml}$ of a $16 \mathrm{~h}$ starter culture. Fermenter cultures were sparged with sterile air at $71 \mathrm{~min}^{-1}$ and stirred at 1000 r.p.m. Cells were harvested about $18 \mathrm{~h}$ after inoculation in exponential phase, when the $\mathrm{OD}_{660}$ (after appropriate dilution) had reached 1-4-1:6. At this phase of growth, the oxygen supply was not growth-limiting. Cells were harvested using a pre-cooled Alpha-Laval continuous centrifuge; all subsequent steps were at $4{ }^{\circ} \mathrm{C}$. Harvested cells were washed three times in PIPES buffer $(50 \mathrm{mM}, \mathrm{pH} \mathrm{6.6)}$ containing $8 \mathrm{mM}$ magnesium acetate. The cells from a small portion of the paste were resuspended in 2-3 ml potassium phosphate buffer

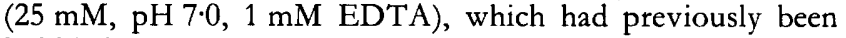
bubbled with $100 \%$ argon gas (BOC) for $1 \mathrm{~h}$. The cell suspension was used immediately for $K_{\mathrm{m}}$ determinations, without freezing. The remaining paste was used to prepare membranes without freezing.

Preparation of cell membranes. This was performed using a modification of the method of Ackrell \& Jones (1971). Washed 
cells (approx. $80 \mathrm{~g}$ wet weight) were resuspended in about $100 \mathrm{ml} 50 \mathrm{mM}$ PIPES buffer (pH 6.5), containing $8 \mathrm{mM}$ magnesium acetate and a few grains of DNase (Sigma). The cell suspension was passed through a French pressure cell (Aminco, Silver Spring, Maryland) at $69 \mathrm{MPa}$. Centrifugation at $27000 \mathrm{~g}$ for $15 \mathrm{~min}$ removed cell debris; membrane vesicles were removed from the supernatant fluid by centrifugation at $100000 \mathrm{~g}$ for $90 \mathrm{~min}$. The membrane pellet was resuspended in the same buffer (10 $\mathrm{ml}$, but lacking DNase) and the suspension was finally dispensed into $300 \mu \mathrm{l}$ aliquots.

Determination of oxygen affinities. Oxygenated soybean leghaemoglobin (a kind gift from Dr F. Bergersen, Division of Plant Industry, CSIRO, Canberra, Australia) and the oxygenated form of sperm whale myoglobin (Sigma, no longer available) were prepared using published methods (Appleby \& Bergersen, 1980). The concentration of myoglobin was determined by $\mathrm{CO}$ difference spectroscopy at room temperature using a Johnson Foundation SDB3 dual-wavelength scanning spectrophotometer and an absorption coefficient of $177 \mathrm{mM}^{-1} \mathrm{~cm}^{-1}$ at $435-420 \mathrm{~nm}$ (Wood, 1984). The concentration of leghaemoglobin was determined from the absolute spectrum of the oxygenated form using the same instrument and an absorption coefficient of $14 \mathrm{mM}^{-1} \mathrm{~cm}^{-1}(575-700 \mathrm{~nm})$ (Appleby \& Bergersen, 1980). Samples of globins were diluted to $10-20 \mu \mathrm{M}$ in potassium phosphate buffer $(25 \mathrm{mM}, \mathrm{pH} 7 \cdot 0)$ containing $1 \mathrm{mM}$ EDTA, which had been previously sparged with a gas mixture (BOC) of $1 \%$ oxygen in argon.

All experiments with leghaemoglobin and myoglobin used the methods and calculations described by Appleby \& Bergersen (1980), except that deoxygenation was monitored by timeshared multi-wavelength spectrophotometry (Chance et al., 1975). The instrument was used in the dual-wavelength mode with interference filters (Omega Optical Inc.) transmitting maximally at $560 \mathrm{~nm}$ (bandpass $2.5 \mathrm{~nm}$ ) and $575 \mathrm{~nm}$ (bandpass $2.0 \mathrm{~nm}$ ). The filters were mounted in an air-driven turbine disc, rotating about an axis parallel to the light beam from a Nikon $50 \mathrm{~W}$ halogen source. The speed of the turbine (driven from a filtered, compressed air supply) provided a chopping frequency of $100 \mathrm{~Hz}$. The photomultiplier was a Thorn-EMI QL-30-RF1 in the 'head-on' configuration. The bandwidth was $1 \mathrm{~Hz}$ giving a rise time of $0.33 \mathrm{~s}$. A specially constructed glass optical cuvette ( $1.3 \mathrm{ml}$ capacity; $1 \mathrm{~cm}$ pathlength; Radley's) was completely filled with a solution (see above) of either oxyleghaemoglobin $(\sim 15 \mu \mathrm{M})$ or oxymyoglobin $(\sim 10 \mu \mathrm{M})$. The cuvette was sealed with a stopper drilled with a fine hole, through which a Hamilton syringe could be inserted. Substrate (1 M DL-malate, $10 \mu \mathrm{l})$ was injected into the cuvette. The stability of the oxygenated form of the myoglobin or leghaemoglobin was then checked by monitoring $\Delta A$ for 5-10 min. After addition of the bacteria or membranes $(5-50 \mu \mathrm{l})$, deoxygenation of the oxygencarrying haemoprotein was continuously monitored by plotting the $\Delta A$ between 575 and $560 \mathrm{~nm}$. The traces thus obtained were digitized with a scanner using Apple Scan and Flexitrace software. The rate of oxygen consumption $(V)$ and the mean concentration of free dissolved oxygen $(S)$ were calculated using the method of Bergersen \& Turner (1979) using Microsoft EXCEL software. Graphs were drawn using Cricket Graph and lines fitted using the linear regression feature of that software. The values of $K^{\prime}$ ( $=k$, oxygen dissociation rate $/ k^{\prime}$, association rate) used in these calculations were $786 \times 10^{-9} \mathrm{M}$ (oxymyoglobin) or $50 \times 10^{-9} \mathrm{M}$ (oxyleghaemoglobin) (Appleby \& Bergersen, 1980). Plots of $1 / V$ versus $1 / S$ (Lineweaver-Burke) and of $V$ versus $V / S$ (Eadie-Hofstee) were used to calculate $K_{m}$ values. At least five separate determinations were carried out on each sample; means and SD are presented. Analyses of variance were carried out using Minitab software.

\section{RESULTS}

\section{Basis and validity of the globin deoxygenation method}

Oxygenated soybean leghaemoglobin and sperm whale myoglobin provide dispersed free oxygen at concentrations defined by the kinetic constants of their oxy-

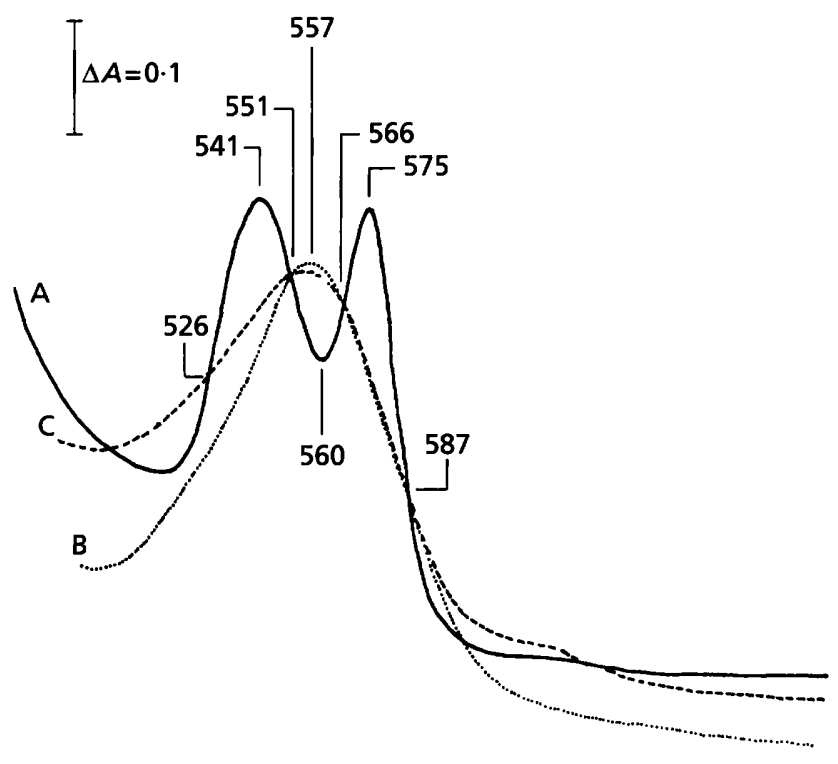

Fig. 1. Absolute spectra at room temperature of leghaemoglobin in the oxygenated $(A, \longrightarrow$ ) and dithionitereduced $(B, \ldots . .$.$) forms and after deoxygenation (C,---)$ elicited by respiration of membranes from $A$. vinelandii strain UW136. Distinctive features of the spectra are marked $(\mathrm{nm})$. The bar represents a $\Delta A$ of $0 \cdot 1$. The pathlength was $1 \mathrm{~cm}$ and the reference wavelength was $575 \mathrm{~nm}$. A baseline (buffer) was recorded and was featureless (not shown).

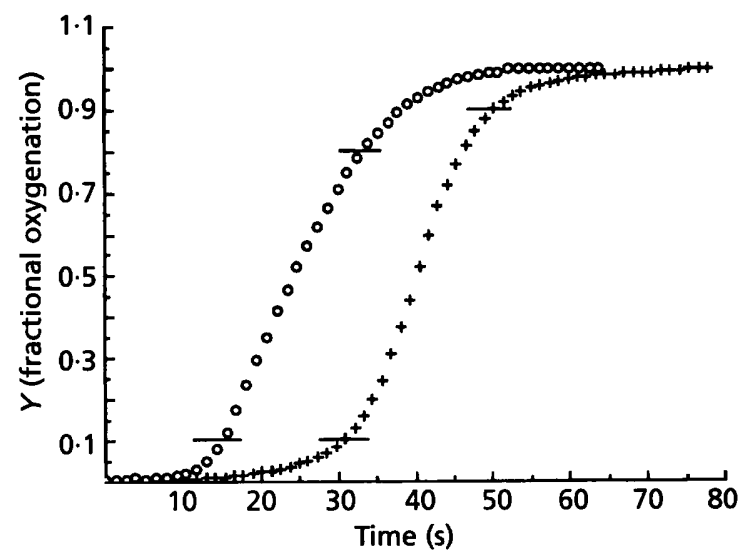

Fig. 2. Deoxygenation kinetics of oxyleghaemoglobin $(O)$ and oxymyoglobin $(+)$ during respiration of intact cells of $A$. vinelandii strain UW136. The lines define, for each oxygen carrier, the fractional oxygenation equivalent to the working range used $(0.3-0.0034 \mu \mathrm{M}$ for oxyleghaemoglobin and $11.6-0.12 \mu \mathrm{M}$ for oxymyoglobin. Only data points between the pairs of lines were used for analysis. 
(a)

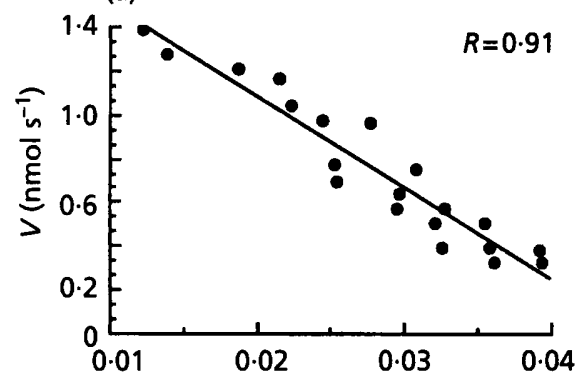

(b)

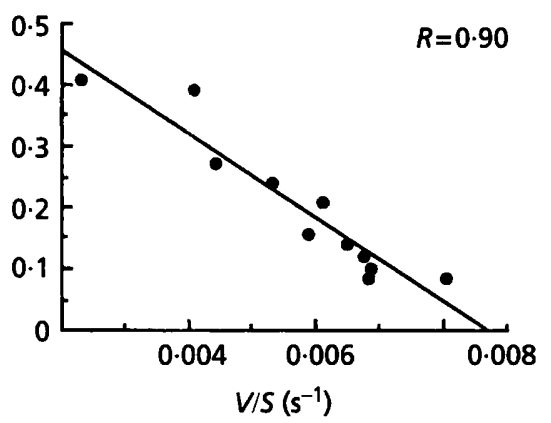

(c)

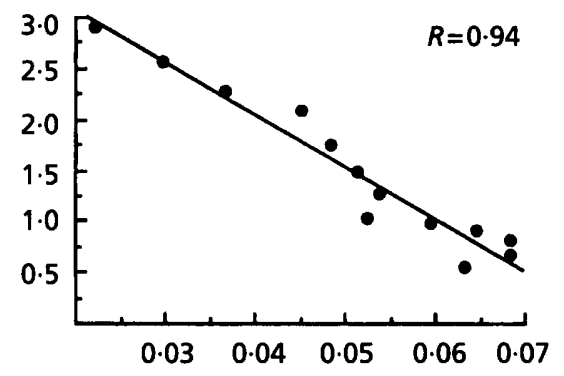

Fig. 3. Eadie-Hofstee plots derived by following the deoxygenation of oxyleghaemoglobin by whole cell preparations of A. vinelandii strains UW136 (a), MK8 (b) and MK5 (c). The calculated $K_{\mathrm{m}}$ values were $0.042,0.068$ and $0.051 \mu \mathrm{M}$, respectively.

Table 1. Oxygen affinities measured in $A$. vinelandii cells and membranes from the deoxygenation kinetics of globins

The $K_{\mathrm{m}}$ values shown were calculated from Eadie-Hofstee plots and are means of five determinations, with SD in parentheses. ND, Not detected.

\begin{tabular}{|lllll|}
\hline \multirow{2}{*}{$\begin{array}{l}\text { Strain and } \\
\text { phenotype }\end{array}$} & $\begin{array}{c}\text { Preparation } \\
\text { type }\end{array}$ & \multicolumn{2}{c|}{$\boldsymbol{K}_{\mathbf{m}}(\boldsymbol{\mu M})$ determined with: } \\
\cline { 3 - 5 } & & Leghaemoglobin & Myoglobin \\
\hline \multirow{2}{*}{ UW136 Cyd ${ }^{+}$} & Whole cells & $0.052(0.016)$ & $0.25(0.066)$ & $2.96(0.96)$ \\
& Membranes & $0.013(0.001)$ & $0.27(0.16)$ & $4.93(2.05)$ \\
MK8 Cyd ${ }^{++}$ & Whole cells & $0.082(0.012)$ & $0.33(0.15)$ & $6.20(1.68)$ \\
& Membranes & $0.019(0.005)$ & $0.43(0.12)$ & $3.71(0.92)$ \\
MK5 Cyd ${ }^{-}$ & Whole cells & $0.032(0.018)$ & $0.30(0.15)$ & ND \\
& Membranes & $0.029(0.012)$ & $0.36(0.31)$ & ND \\
\hline
\end{tabular}

genation and deoxygenation, and their optical spectra indicate the average oxygen concentration (Appleby \& Bergersen, 1980: Bergersen \& Turner, 1979, 1980). The visible absorption spectrum of oxyleghaemoglobin (Fig. 1 ) is characterized in the $\alpha$ and $\beta$ regions by maxima at 541 and $575 \mathrm{~nm}$. In contrast, the deoxygenated (reduced) form has a single broad $\beta$ band at $557 \mathrm{~nm}$. Thus, measuring absorbance changes at $560 \mathrm{~nm}$ minus $575 \mathrm{~nm}$ monitors the oxy-deoxy transition that accompanies respiration and oxygen removal from solution. The peaks of the oxy forms of myoglobin are at 542 and $\sim 582 \mathrm{~nm}$ and are at sufficiently similar wavelengths to that of oxyleghaemoglobin (Bergersen \& Turner, 1979; Wood, 1984) to allow use of the same filters with only slight loss in sensitivity.

Three $A$. vinelandii strains were investigated, the wildtype strain UW136, a Cyd ${ }^{-}$mutant (MK5) and a strain (MK8) over-producing the cytochrome $b d$ complex. The deoxygenations of oxymyoglobin and oxyleghaemoglobin were followed with both cells and membrane preparations from all three strains. The $V_{\max }$ values for oxygen consumption in these strains (as measured in an oxygen electrode) differed. For membrane particles oxidizing malate, the value for $\mathrm{MK} 5\left(\mathrm{Cyd}^{-}\right)$was about onetenth of that for UW136, as reported by Kelly et al. (1990). The value for MK8 $\left(\mathrm{Cyd}^{++}\right)$was one-half of the wild-type value. The volumes of cell and membrane suspensions used for $K_{\mathrm{m}}$ measurements were adjusted so as to obtain deoxygenation of the globin in a convenient time.

A number of precautions and controls were introduced to ensure that the absorbance changes measured the deoxygenation kinetics. Firstly, absorbance at these wavelengths was unaffected by the presence of $A$. vinelandii membranes or cells in the cuvette. In the experiment shown in Fig. 1, for example, clear isosbestic points in the spectra for the oxygenated form of leghaemoglobin, the dithionite-treated form, and the form resulting from deoxygenation by the sample, were observed despite the presence of membranes. Secondly, doubling the cell or membrane concentration, when the leghaemoglobin concentration was in the range $13-20 \mu \mathrm{M}$, was without effect on the measured $K_{\mathrm{m}}$ values. Thirdly, to ensure that the 

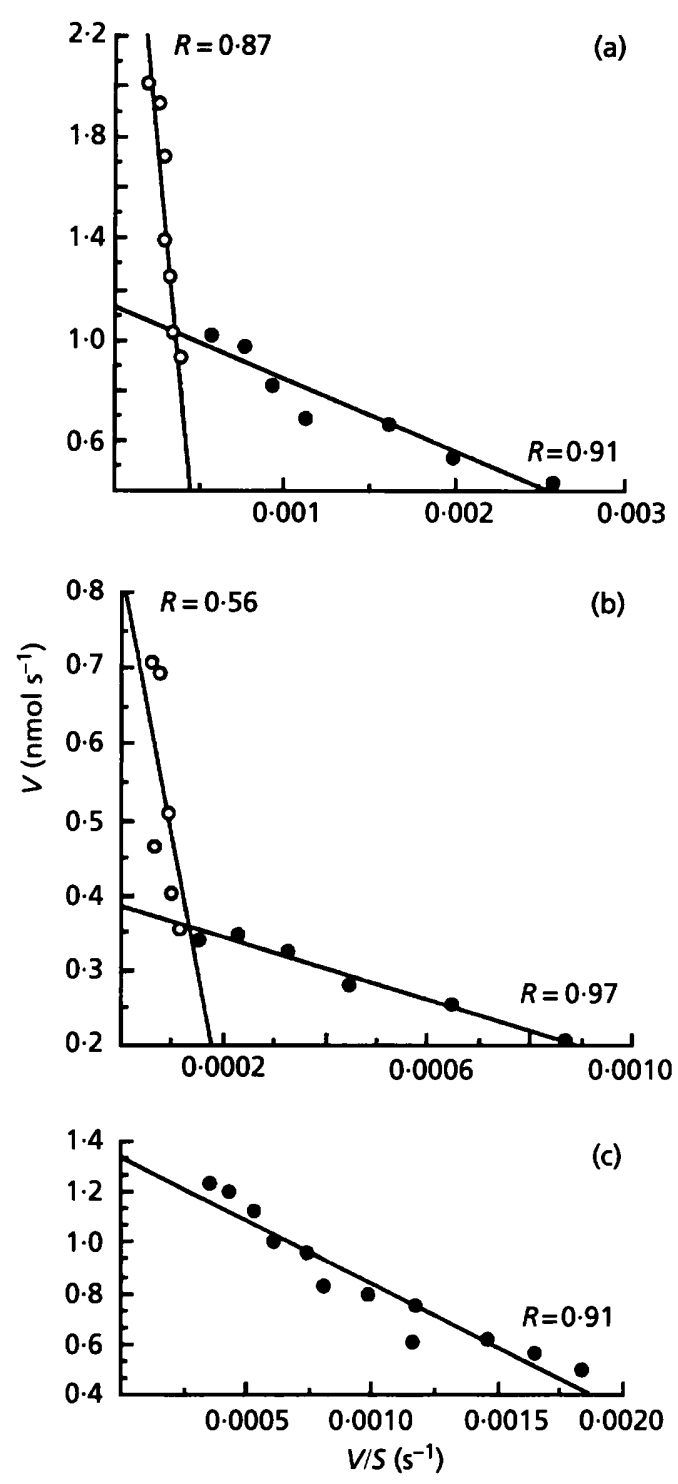

Fig. 4. Eadie-Hofstee plots derived by following the deoxygenation of oxymyoglobin by whole cell preparations of A. vinelandii strains UW136 (a), MK8 (b) and MK5 (c). The calculated $K_{m}$ values were 6.52 and $0.29 \mu \mathrm{M}$ for UW136, 3.53 and $0.20 \mathrm{mM}$ for MK8, and $0.50 \mu \mathrm{M}$ for MK5. Closed and open symbols in (a) and (b) define the low and high affinity components, respectively.

absorbance changes were attributable to deoxygenation of the globin and not oxidation, the cuvette contents were examined in the wavelength-scanning instrument before and after each deoxygenation experiment. Spectra were scanned using a buffer blank and were used to calculate the concentrations of the oxy and deoxy forms. A typical spectrum of leghaemoglobin deoxygenated by respiration (Fig. 1) shows the disappearance of the peaks at 541 and $575 \mathrm{~nm}$ and their replacement by a peak at $557 \mathrm{~nm}$ characteristic of the deoxygenated form. In the Soret region (not shown), the $411 \mathrm{~nm}$ peak of the oxygenated form was replaced by a broad band with a lower $\varepsilon$ and a maximum at $427 \mathrm{~nm}$, attributable largely to the deoxy form. The weak band at $627 \mathrm{~nm}$ (Fig. 1) suggests some formation of the ferric form, but the expected Soret band of the ferric form (at $404 \mathrm{~nm}$ ) was undetectable. In the calculation of results, full deoxygenation is taken as that level attained by respiration and not that achieved by dithionite; this avoids the problems caused by partial oxidation during the reaction or $\mathrm{Fe}(\mathrm{III})$ impurities in the globin sample used. Addition of dithionite to a sample deoxygenated by respiration elicited $<5 \%$ change at the wavelength pair used. Although detailed above and in Fig. 1 for leghaemoglobin, similar control experiments with myoglobin (generally used at about $10 \mu \mathrm{M}$ ) gave similar results.

At time $t$, the total oxygen present in the reaction is given by

$$
\mathrm{O}_{2_{\text {total }}}=V_{\mathrm{f}}\left(Y C+\left[\mathrm{O}_{2_{\text {free }}}\right]\right)
$$

where $V_{\mathrm{f}}$ is the reaction volume, $C$ is the concentration of globin and the free oxygen concentration, $\left[\mathrm{O}_{2_{\text {pree }}}\right]$, is given by $K^{\prime} Y / 1-Y$. $K^{\prime}$ is the dissociation constant (see Methods) and $Y$ is the fractional oxygenation at time $t$ given by the data, such as presented for whole organisms of strain UW136 in Fig. 2. Oxyleghaemoglobin allows oxygen consumption rates to be measured when the free oxygen concentration in the reaction $\left(\left[\mathrm{O}_{2_{p r e p}}\right]\right)$ is in the range $0.003-0.3 \mu \mathrm{M}$ (Bergersen \& Turner, 1980). Only data that fell in this range (calculated as shown above) were examined (as indicated in the example in Fig. 2). Oxymyoglobin allows oxygen consumption rates to be measured in the range $0 \cdot 1-10 \mu \mathrm{M}$. Similarly, only data that fell in this range were examined.

\section{Deoxygenation of oxyleghaemoglobin by A. vinelandii cells and membranes}

All experiments with leghaemoglobin as the source of oxygen revealed a single component in Eadie-Hofstee plots. Fig. 3 shows the plots for results obtained for whole cells using oxyleghaemoglobin. The $K_{\mathrm{m}}$ values measured with whole organisms of strains UW136, MK8 and MK5 were $0.052,0.082$ and $0.032 \mu \mathrm{M}$, respectively (each a mean of five replicate determinations). The results for all three strains and the membranes prepared from them (plots not shown) are summarized in Table 1 . In MK5 $\left(\mathrm{Cyd}^{-}\right)$, this highest affinity component had a $K_{\mathrm{m}}$ of about $0.03 \mu \mathrm{M}$ in both cells and membranes. A one-way analysis of variance for the data obtained with MK5 cells and membranes gave $P=0.79$, indicating no statistically significant difference between the data sets. However, in UW136 and MK8 (both $\mathrm{Cyd}^{+}$), the $K_{\mathrm{m}}$ measured for membranes was markedly (about fourfold) lower than the value for intact cells, when malate was the substrate for all preparations. A one-way analysis of variance for the data obtained, for example, with MK8 cells and membranes gave $P=0.0078$, indicating a statistically significant difference between the data sets. These results suggest restriction in whole cells of the transfer of oxygen from the medium (in which oxyleghaemoglobin monitors dissolved oxygen concentration) to the active site of the highest affinity oxidase. This oxidase cannot be cytochrome $b d$ since an activity with such a $K_{\mathrm{m}}$ was present in all three strains. 
Table 2. Comparison of the apparent affinities $\left(K_{m^{\prime}} \mu \mathrm{M}\right)$ for oxygen of some bacterial terminal oxidases

The Table shows $K_{m}$ values obtained by use of oxygen electrodes (E), or from the deoxygenation kinetics of leghaemoglobin (L) or myoglobin (M).

\begin{tabular}{|c|c|c|c|c|}
\hline Organism & $\begin{array}{c}\text { Purified } \\
\text { o-type } \\
\text { oxidase }\end{array}$ & $\begin{array}{l}\text { Purified } \\
b d \text {-type } \\
\text { oxidase }\end{array}$ & Membranes & Whole cells \\
\hline E. coli & $3.0(E)^{\mathrm{a}}$ & $0.4(E)^{\mathrm{a}}$ & $1 \cdot 0,0 \cdot 2(\mathrm{E})^{\mathrm{a}}$ & $\begin{array}{l}2 \cdot 0,0 \cdot 3(\mathrm{E})^{\mathrm{a}} \\
0 \cdot 2,0.02(\mathrm{E})^{\mathrm{b}}\end{array}$ \\
\hline K. pneumoniae & & $0.02(\mathrm{~L})^{\mathrm{c}}$ & & $25,0 \cdot 1(\mathrm{~L}, \mathrm{M})^{\mathrm{d}}$ \\
\hline A. chroococcum & & & $<0.5(\mathrm{E})^{\mathrm{e}}$ & $20,5-10(E)^{e}$ \\
\hline \multirow{3}{*}{ A. vinelandii } & & & $18,3(\mathrm{E})^{8}$ & $35,0.5(\mathrm{~L}, \mathrm{M})^{\mathrm{d}}$ \\
\hline & & & $5(E)^{g}$ & $55-59,10(\mathrm{E})^{\mathrm{g}}$ \\
\hline & & & $4 \cdot 9,0 \cdot 27,0 \cdot 013(\mathrm{~L}, \mathrm{M})^{\mathrm{h}}$ & $3,0 \cdot 25,0 \cdot 05(\mathrm{~L}, \mathrm{M})^{\mathrm{h}}$ \\
\hline
\end{tabular}

References: a, Kita et al. (1984); b, Rice \& Hempfling (1978); c, Smith et al. (1990); d, Bergersen \& Turner (1980); e, Ramos \& Robson (1985); f, Hoffman et al. (1979); g, Peterson (1989); h, this paper.

\section{Deoxygenation of oxymyoglobin by $A$. vinelandii cells and membranes}

Oxymyoglobin was used to provide data in the range $0 \cdot 1-10 \mu \mathrm{M}$ oxygen. Both the wild-type and the cytochrome $d$-over-producing strain revealed two components in either Eadie-Hofstee plots (Fig. 4a, b) or Lineweaver-Burke plots (not shown). Table 1 summarizes the $K_{\mathrm{m}}$ values obtained. A one-way analysis of variance indicated that, for UW136 cells, for example, the two affinities measured with oxymyoglobin were significantly different $(P=0 \cdot 0015)$ and that the component with the lower $K_{\mathrm{m}}$ value was significantly different $(P=0.0062)$ from that measured with oxyleghaemoglobin. Comparisons of the three affinities gave $P \sim 0.000$. For whole cells, the mean $K_{\mathrm{m}}$ values of the higher affinity component were $0.25 \mu \mathrm{M}$ for the wild-type and $0.33 \mu \mathrm{M}$ for the over-producing strain and were not markedly different when membrane preparations were analysed. The cytochrome $b d$-deficient mutant MK5 also exhibited an oxidase activity with a $K_{\mathrm{m}}$ value in this range. However, both the wild-type (Fig. $4 \mathrm{a}$ ) and the cytochrome $d$-over-producing strain (Fig. 4b) also revealed a component of low affinity with a $K_{\mathrm{m}}$ value in the range 3-6.2 $\mu \mathrm{M}$ (Table 1). Strikingly, the data for the cytochrome $b d$-deficient mutant (Fig. 4c) revealed a monophasic plot with no evidence for a component having an affinity in this range. This demonstrates that the lowest affinity component detected in UW136 and MK8, with a mean $K_{\mathrm{m}}$ of about $4.5 \mu \mathrm{M}$, is attributable to the cytochrome $b d$-type oxidase.

\section{DISCUSSION}

\section{The use of oxygenated globins as reporters of oxygen consumption}

We have employed the method utilizing the kinetics of oxygen binding by haemoglobins, devised by Bergersen \& Turner (1979), to measure oxygen consumption by whole cells and membrane preparations of $A$. vinelandii strains. This method has two advantages over the use of conventional oxygen electrodes. Firstly, oxygen gradients, which are associated with the membranes separating the sensor from the sample (Lundsgaard et al., 1978; Bergersen \& Turner, 1985) are avoided. Secondly, the sensitivity of the measurement is much greater (working range for leghaemoglobin, $0.003-0.1 \mu \mathrm{M}$; for sperm whale myoglobin, $0 \cdot 1-10 \mu \mathrm{M})$. The sensitivity of oxygen electrodes is generally only about $1 \mu \mathrm{M}$, although with suitable amplification oxygen concentrations as low as $0 \cdot 1 \mu \mathrm{M}$ may be detected (Bergersen \& Turner, 1985). By using a timesharing, multi-wavelength spectrophotometer, we have been able to monitor continuously two wavelengths reporting the loss of absorbance of the oxygenated form and formation of the deoxy form of the globin during oxygen uptake by $A$. vinelandii. This procedure differs from that of Bergersen \& Turner (1979) who recorded alternately the absorbance signals of the oxy and deoxy forms, from which the computed difference was used to calculate the average dissolved oxygen concentration during one cycle of data acquisition. Our procedure more clearly reveals the different progress of deoxygenation kinetics for the two globins. The profiles (Fig. 2) reflect the differences in $k$ and $k^{\prime}$ of the globins in relation to the respiratory properties of the bacterial samples.

\section{Cytochrome bd in A. vinelandii is a low affinity oxidase}

The use of myoglobin as oxygen sensor revealed the presence of two oxygen uptake activities in all strains except the $\mathrm{Cyd}^{-}$mutant. Because the lower affinity component was absent in the $\mathrm{Cyd}^{-}$mutant, this activity ( $K_{\mathrm{m}} 3-6.2 \mu \mathrm{M}$ in whole cells) can be assigned to the cytochrome $b d$-type oxidase. The affinities measured here are compared with those reported elsewhere for Azotobacter and for oxidases from enteric bacteria in Table 2. We emphasize that the precision of many of these 
measurements is questionable, since oxygen electrodes were used for analysis. Despite the differences in approach, some general points can be made about the data in Table 2. Firstly, in the enteric bacteria, there is good evidence that the cytochrome $b d$-type oxidase, which is produced under conditions of low oxygen supply, has a high oxygen affinity. Secondly, in Azotobacter, environmental factors other than changes in the supply of oxygen influence the apparent oxygen affinity, such as the nature of the carbon and energy source (Ramos \& Robson, 1985) and the concentrations of $\mathrm{Mg}^{2+}$ and $\mathrm{Ca}^{2+}$ (Peterson, 1989). In the present study, all strains were grown to exponential phase in a sucrose medium with $\mathrm{NH}_{4}^{+}$as source of $\mathrm{N}$ and adequate aeration so as to minimize the effects of nutrient limitation on oxidase synthesis and function. In such cells, the cytochrome $b d$-type oxidase clearly has the lowest affinity for oxygen of the three activities detected.

\section{The high affinity oxidase revealed with oxyleghaemoglobin}

The kinetics of oxygen uptake obtained using leghaemoglobin revealed a high affinity oxidase in all strains. However, the values measured were significantly different, in cytochrome $b d$-containing strains, according to whether membranes or intact cells were used. Since the membrane vesicles used were prepared in the French pressure cell, it is likely that a significant fraction will be inverted (Poole, 1993), exposing the oxygen-consuming site of the high-affinity oxidase (which presumably faces the cytoplasm in vivo) to the medium. A possible explanation for the difference in apparent $K_{\mathrm{m}}$ values for the highest affinity component in cells and membranes of cytochrome $b d$-containing strains is that cytochrome $b d$ competes effectively with the highest affinity oxidase by exhibiting a very fast 'on' rate for oxygen binding and formation of the oxygenated species (Poole et al., 1983). Such a fast 'on' rate is not necessarily inconsistent with the low overall affinity for oxygen reduction measured in the present study. An alternative explanation is that the presence of the cytochrome $b d$-type oxidase limits access of oxygen in the bulk phase to the highest affinity oxidase because the oxygen-binding site of the former is on the outer face of the cytoplasmic membrane in vivo. In E. coli, measurements of respiration-driven proton translocation (Miller \& Gennis, 1985; Puustinen et al., 1991) suggest that protons are consumed in oxygen reduction on the cytoplasmic (inner) face of the membrane and, together with proton ejection from quinol oxidation on the outer face, result in net proton translocation outwards; the organization of the cytochrome $b d$-type oxidase has not been studied in $A$. vinelandii.

\section{A third oxidase?}

Bergersen \& Turner (1980) also reported the affinity for oxygen of $A$. vinelandii respiration using the oxygencarrying haemoprotein method. In cells that had been grown in a chemostat at $0.1 \mu \mathrm{M} \mathrm{O}_{2}$, a $K_{\mathrm{m}}$ of $0.48 \mu \mathrm{M}$ was found, which is presumably equivalent to the component with a $K_{\mathrm{m}}$ close to $0.3 \mu \mathrm{M}$ found in the work presented here, but which cannot yet be assigned to a particular oxidase. Taking into account the extreme conditions of low dissolved oxygen in steady state under which the cells were grown, it is perhaps not surprising that only one oxidase of high affinity was observed. A third terminal pathway to oxygen has been proposed, but characterized only by its extreme insensitivity to cyanide (Kauffman \& van Gelder, 1974). It carries about $5 \%$ of the total electron flux and may involve autoxidation of a $b$-type cytochrome. The possibility of a third oxidase can be tested only when mutants defective in both cytochromes $b d$ and $o$ are obtained. Such experiments are under way in this laboratory.

\section{Cytochrome bd in respiratory protection}

The evidence for the involvement of the cytochrome $b d$ type oxidase in the phenomenon of respiratory protection of nitrogenase in Azotobacter can be summarized as follows. (1) The level of this oxidase is increased when the supply of oxygen to a culture is increased (Drozd \& Postgate, 1970; reviewed by Hill, 1992). (2) Under these conditions, consumption of carbon and energy sources is partially uncoupled from anabolism (Dalton \& Postgate, 1969), and there appears to be preferential electron transport to the cytochrome $b d$-type oxidase, which could result in by-passing the energy conservation site associated with the cytochrome o-type oxidase (Jones et al., 1973). (3) Mutants affected in the structural genes encoding the cytochrome $b d$-type oxidase lack the characteristic aero-tolerant diazotrophy of wild-type Azotobacter and fix nitrogen only under microaerobic conditions (Kelly et al., 1990). The present results demonstrate that the cytochrome $b d$-type oxidase is of low affinity, but do not establish whether this kinetic property is a consequence of the high oxygen consumption rates exhibited by this oxidase. The relationship between oxidase activity and oxygen affinity, and an explanation of the disparate affinities exhibited by the structurally similar cytochrome $b d$-type oxidases in $A$. vinelandii and $E$. coli, remain problems to be addressed by future studies.

\section{ACKNOWLEDGEMENTS}

This work was supported by the SERC through a CASE Studentship (R.D.M.), the AFRC through a Linked Research Grant (S.H., R.K.P.), and the Royal Society through equipment grants and a Leverhulme Trust Senior Research Fellowship (R.K.P.). We also thank Dr C. A. Appleby for stimulating discussion, Dr F. J. Bergersen for gifts of globins and helpful advice, and Dr A. Pentecost for assistance with statistical analyses.

\section{REFERENCES}

Ackrell, B. A. C. \& Jones, C. W. (1971). The respiratory system of Azotobacter vinelandii. 1. Properties of phosphorylating membranes. Eur J Biochem 20, 22-28.

Appleby, C. A. \& Bergersen, F. J. (1980). Preparation and experimental use of leghaemoglobin. In Methods of Evaluating Biological Nitrogen Fixation, pp. 315-335. Edited by F. J. Bergersen. Chichester: John Wiley and Sons. 
Bergersen, F. J. \& Turner, G. L. (1979). Systems utilizing oxygenated leghaemoglobin and myoglobin as sources of free dissolved oxygen at low concentrations for experiments with bacteria. Anal Biochem 96, 165-174.

Bergersen, F. J. \& Turner, G. L. (1980). Properties of terminal oxidase systems of bacteroids from root nodules of soybean and cowpea and of $\mathrm{N}_{2}$-fixing bacteria grown in continuous culture. $J$ Gen Microbiol 118, 235-252.

Bergersen, F. J. \& Turner, G. L. (1985). Measurements of components of proton motive force and related parameters in steady state, microaerobic conditions. J Microbiol Methods 4, 13-23.

Chance, B., Legallais, V., Sorge, J. \& Graham, N. (1975). A versatile time-sharing multichannel spectrophotometer, reflectometer and fluorometer. Anal Biochem 66, 498-514.

Cotter, P. A., Chepuri, V., Gennis, R. B. \& Gunsalus, R. P. (1990). Cytochrome $o$ (cyoABCDE) and $d(c y d A B)$ oxidase gene expression in Escherichia coli is regulated by oxygen, $\mathrm{pH}$ and the fnr gene product. $J$ Bacteriol 172, 6333-6338.

Dalton, H. \& Postgate, J. R. (1969). Effect of oxygen on growth of Azotobacter chroococcum in batch and continuous cultures. $J$ Gen Microbiol 54, 463-473.

Drozd, J. \& Postgate, J. R. (1970). Effects of oxygen on acetylene reduction, cytochrome content and respiratory activity of Azotobacter cbroococcum. J Gen Microbiol 63, 63-73.

Haaker, H. \& Veeger, C. (1976). Regulation of respiration and nitrogen fixation in different types of Azotobacter vinelandii. Eur $J$ Biochem 63, 499-507.

Haddock, B. A. \& Jones, C. W. (1977). Bacterial respiration. Bacteriol Rev 41, 47-99.

Hill, S. (1988). How is nitrogenase regulated by oxygen? FEMS Microbiol Lett 54, 111-130.

Hill, S. (1992). Physiology of nitrogen fixation in free-living heterotrophs. In Biological Nitrogen Fixation, pp. 87-134. Edited by G. Stacey, R. H. Burris \& H. J. Evans. London, New York: Chapman and Hall.

Hoffman, P. S., Morgan, T. V. \& Dervartanian, D. V. (1979). Respiratory-chain characteristics of mutants of Azotobacter vinelandii negative to tetramethyl-p-phenylenediamine oxidase. Eur J Biochem $100,19-27$.

Jones, C. W., Brice, J. M., Wright, V. \& Ackrell, B. A. C. (1973). Respiratory protection of nitrogenase in Azotobacter vinelandii. FEBS Lett 29, 77-81.

Junemann, S. \& Wrigglesworth, J. M. (1993). Stoichiometry of CO binding to the cytochrome bd complex of Azotobacter vinelandii. Biochem Soc Trans 21, 345S.

Jurtshuk, P., Mueller, T. J. \& Wong, T. Y. (1981). Isolation and purification of the cytochrome oxidase of Azotobacter vinelandii. Biocbim Biopbys Acta 637, 374-382.

Kauffman, H. F. \& van Gelder, B. F. (1974). The respiratory chain of Azotobacter vinelandii. III. The effect of cyanide in the presence of substrates. Biocbim Biophys Acta 333, 218-227.

Kelly, M. J. S., Poole, R. K., Yates, M. G. \& Kennedy, C. (1990). Cloning and mutagenesis of genes encoding the cytochrome bd terminal oxidase complex in Azotobacter vinelandii: mutants deficient in the cytochrome $d$ complex are unable to fix nitrogen in air. $J$ Bacteriol 172, 6010-6019.

Kita, K., Konishi, K. \& Anraku, Y. (1984). Terminal oxidases of Escherichia coli aerobic respiratory chain. I. Purification and properties of cytochrome $b_{562}-0$ complex from cells in the early exponential phase of aerobic growth. J Biol Chem 259, 33683374.

Lundsgaard, J. S., Grolund, J. \& Degn, H. (1978). Errors in oxygen measurements in open systems owing to oxygen consumption in unstirred layer. Biotechnol Bioengineering 20, 809-819.

Mclnery, M. J., Holmes, K. S., Hoffman, P. \& Der-Vartanian, D. V. (1984). Respiratory mutants of Azotobacter vinelandii with elevated levels of cytochrome $d$. Eur J Biochem 141, 447-452.

Miller, M. J. \& Gennis, R. B. (1985). The cytochrome $d$ complex is a coupling site in the aerobic respiratory chain of Escherichia coli. $J$ Biol Chem 260, 14003-14008.

Moshiri, F., Chawla, A. \& Maier, R. J. (1991). Cloning, characterization, and expression in Escherichia coli of the genes encoding the cytochrome $d$ oxidase complex from Azotobacter vinelandii.J Bacteriol 173, 6230-6241.

Peterson, J. B. (1989). Respiratory differences associated with culture aeration in Azotobacter vinelandii. Can J Microbiol 35, 918-924.

Poole, R. K. (1983). Bacterial cytochrome oxidases: a structurally and functionally diverse group of electron-transfer proteins. Biochim Biopbys Acta 726, 205-243.

Poole, R. K. (1988). Bacterial cytochrome oxidases. In Bacterial Energy Transduction, pp. 231-291. Edited by C. Antony. London: Academic Press.

Poole, R. K. (1993). The isolation of membranes from bacteria. In Methods in Molecular Biology, vol. XIX: Biomembrane Protocols: Isolation and Analysis, pp. 109-122. Edited by J. M. Graham and J. A. Higgins. Totowa, NJ: Humana Press.

Poole, R. K., Kumar, C., Salmon, I. \& Chance, B. (1983). The $650 \mathrm{~nm}$ chromophore in Escherichia coli is an 'oxy-' or oxygenated compound, not the oxidized form of cytochrome oxidase $d$ : a hypothesis. J Gen Microbiol 129, 1335-1344.

Puustinen, A., Finel, M., Haltia, T., Gennis, R. B. \& Wikstrom, M. (1991). Properties of the two terminal oxidases of Escherichia coli. Biochemistry 30, 3936-3942.

Ramos, J. L. \& Robson, R. L. (1985). Isolation and properties of mutants of Azotobacter chroococcum defective in aerobic nitrogen fixation. J Gen Microbiol 131, 1449-1458.

Rice, C. W. \& Hempfling, W. P. (1978). Oxygen-limited continuous culture and respiratory energy conservation in Escherichia coli. $J$ Bacteriol 134, 115-124.

Robson, R. L. \& Postgate, J. R. (1980). Oxygen and hydrogen in biological nitrogen fixation. Annu Rev Microbiol 34, 183-207.

Smith, A., Hill, S. \& Anthony, C. (1990). The purification, characterization and role of the $d$-type cytochrome oxidase of Klebsiella pneumoniae during nitrogen fixation. J Gen Microbiol 136, 171-180.

Wood, P. M. (1984). Bacterial proteins with CO-binding $b$ - or $c$ type haem. Functions and absorption spectroscopy. Biochim Biophys Acta 768, 293-317.

Yang, T. (1986). The biochemical and biophysical properties of cytochrome $o$ of Azotobacter vinelandii. Biochim Biophys Acta 848, 342-351.

Yates, M. G. (1988). The role of oxygen and hydrogen in nitrogen fixation. In The Nitrogen and Sulphur Cycles, pp. 383-416. Edited by J. A. Cole \& S. J. Ferguson. Cambridge: Cambridge University Press.

Received 30 September 1993; revised 28 December 1993; accepted 7 January 1994. 